\title{
The Skills of Teacher's Questioning in English Classes
}

\author{
Xiaoyan Ma \\ School of Foreign Languages \\ Yangtze Normal University \\ 98 Julong Road, Lidu, Fuling \\ Chongqing 408100, China \\ E-mail: eileen1860@msn.com
}

\begin{abstract}
English is a main subject in Chinese English classes, which requires plenty of practice, needs cooperation between the teacher and students in class to jointly fulfill the verbal communication and the teaching-learning procedure. Classroom questioning, the skill of the elicitation method of teaching that is student-oriented and advocated today, gives an incentive to communicative activities in English. Raising questions effectively is a major method of the teacher who guides his students to think actively, fostering students' ability of analysis and creation. It is also an essential way for the teacher to output information and obtain feedback, and an important channel to exchange ideas between the teacher and students. Therefore, the teacher must pay great attention to the skill of asking questions in English class. Each question must be presented to accomplish the teaching objective and task. Only in this way may the English teachers ask question effectively and improve the skill of questioning so as to make contribution to our Chinese English education.

To begin with some elemental definitions, this paper discusses some basic knowledge of questions, and then explores the skill of questioning in English class about the preparing, designing, controlling and evaluating of questioning. Finally the benefit of the skill is studied with abundant teaching cases. The paper analyzes tentative in English class by integrating theory with practice. Thus, the skills of questioning are further understood in English classes.
\end{abstract}

Keywords: English teaching, Questioning, Skills, Interaction teaching

\section{Introduction}

As the education has already welcomed the 21st century's dawn, we has entered the personal digitization information age, and it have appeared many changes in classroom teaching and in the students' activities since the educational reform. Teaching has become more scientific, interesting and vivid. Teachers' questioning has traditionally been viewed as an important component of teacher talk and the core of effective teaching in classroom context. (Note 1) Asking questions is one of the most common teaching tactics used. Qualitative questions directly influence the classroom activities. Effective questions depend on the using of teachers' skills.

A common problem that EFL (English as a foreign language) teachers are facing is to deal with a passive class, where students are unresponsive and avoid interaction with the teacher. This is especially true when a teacher seeks interaction in a teacher-class dialog, such as asking questions to the class as a whole, expecting at least one student to respond. This can be a frustrating experience for the two sides. Obviously, there will be time when no student can answer a teacher's question. However, students often are reluctant to made response even if they understand the questions, know the answers, and are able to produce the answers. What more, students are rather reluctant to give feedback. The students, as a whole, don't respond voluntarily to the instructor's questions and don't participate in class discussions. Most of the class members sit looking straight ahead using minimal facial expressions, gestures and verbal utterances. Thus the teachers receive little oral feedback. What the teachers want are the students to be more positive and overtly communicative in their feedback.

It is necessary for teachers to understand how the dynamics of classroom communication influence students' perceptions and participation in classroom activities, and then it may enable them to monitor and adjust the patterns of classroom communication in order to create an environment that is conducive to both classroom learning and second language acquisition. Classroom is regarded as a unique communication context. The patterns of classroom communication ultimately determine students' participation in classroom activities by using the language, and the opportunities and efficiency of the target language acquisition. One of the key language teaching methods is to use questioning as a learning tool to promote classroom interaction. Questions are easy to "trigger" thinking, ignite inquiry 
and establish dialogic relationships. However, it is important to know that not all questions achieve these.

Being a teacher, have you ever thought about the questions you ask your students? How do your teacher-student interactions change depending on the questions you ask? What kind of questions and structures will get the best results from your students?

Questioning plays an important role in teacher talk which is considered to have a potential effect on learners' comprehension, and which has been hypothesized to be important for Second Language Acquisition (SLA). (Note 2) Certain skills are involved in the questioning process. What kind of questioning skills to choose is totally different to individual teachers? Teachers' personal taste, educational beliefs and cultural background may have an impact on their own choice and application of strategies. Nowadays mutual communications between different races and areas are becoming more frequently than ever before.

\section{Basic Knowledge of Questioning in English Classes}

As one may deduce, questioning is one of the most popular modes of teaching. Classroom questioning is a common and traditional teaching method. (Note 3) Almost all the teachers ask questions in class every day, but most of them are raised casually.

\subsection{Importance of Questioning in English Classes}

Questioning is a common technique used in English language teaching. The goal is to check if the students understand what they have been taught, and to enhance students' involvement and to promote students' creative thinking in classroom interaction. Questioning has been considered as one of the most essential and important techniques during instructional processes since Socrates times. Questioning takes up most of teacher talk and it has been improved to have a great influence on classroom interaction. Questioning has always been the most ubiquitous phenomenon observed in classroom, as well as one of the most frequently-adopted devices favored by most of the teachers.

Questioning is one kind of teaching active procedure. It is one teaching behavior way through teachers and students' interaction, checking learning, promoting thought, consolidating knowledge, using knowledge, achieving teaching goals. Questioning is usually used as one kind of mutual exchange teaching skills between the teacher and students. It has been used widely in teaching till now.

Classroom questioning is the main part of classroom teaching, and is one of the teaching methods to get the aim of classroom teaching. Teachers want to get students' responses and the first step is to answer questions. Through consistent dialog and communication again, the teacher can get the answers they want and evaluate the students. Questioning, as a general way used by teachers in class, plays an important role in classroom teaching. Questions are used to evaluate students' knowledge and understanding of subject matter. Questions can help to review essential content in a subject. Questions can be used to control the social behavior of students.

\subsection{Types of Questioning in English Classes}

Much of teachers' talk relates to questions (Note 4) and substantial research exists demonstrating that questions can assist learners in improving their linguistic ability. (Note 5) Chaudron goes further, warning that poor questioning practice can be counter-productive.

Studies of questioning have proposed various categories of questions, and questions can be classified by the type of response they solicit or the purpose they serve. A taxonomy of question types is given as Table 1 .

All of these types of questions have their places in the interactive classroom. Among all the types of questions, the distinction between "display" and "referential" question is an important one given the emphasis on meaningful communication in the language classroom. That is, in social communication, people do not generally ask questions to which they already know the answer. Besides the fact that the questioner genuinely wants to know the answer in this case, the meaning of an utterance is also subject to negotiation between the speaker and the hearer. However, this kind of negotiation of meaning is often absent in the classroom. The meaning of the teacher's question and what constitutes an appropriate answer is usually predetermined by the teacher. Therefore, it is necessary to point out the advantages and the disadvantages of display and referential questions. A further classroom research study has been carried out into the use of display and referential questions in language classrooms. And it will be analyzed later in the part of "Skills of Designing for Questioning”.

\subsection{The Role and Function of Question}

Questions in the class serve as different functions. According to Kauchak and Eggert, the functions can be basically grouped into three categories: diagnostic, instructional and motivational, but a single question can usually serve more than one function. As a diagnostic tool, classroom questions allow the teacher to glimpse into the minds of students to find out not only what they know or don't know but also how they think about a topic. (Note 8) The instructional function means that questions can be used as a technique to facilitate learners to learn the new knowledge in the 
learning process. As to motivational function, skillful use of questions can effectively involve students in the classroom discourse, encouraging and challenging them to think.

In terms of its functions, there are several detailed reasons why questions are so commonly used in teaching and learning:

- They stimulate and maintain students' interest.

- They encourage students to think and focus on the content of the lesson. They enable a teacher to clarify what a student has said.

- They enable a teacher to elicit a particular structure or vocabulary items.

- They enable teachers to check students' understanding.

- They encourage student participation in a lesson.

Cited from Richards\&Lockhart (Note 9)

Besides its various functions, the author wants to draw attention to the point that questions can also contribute a lot to the classroom interaction structure. As a two-way interaction, questioning process has its potential to stimulate students' interaction, thinking and learning. (Note 10) The use of questions can thus change the way of teacher monologue and involve students in the active classroom interaction, which is much helpful to the development of their language competence.

As for teachers' questioning, there are still many problems. First, many high school teachers are not fully aware of the effects of teachers' questioning on classroom interaction. Second, they pay little attention to the strategies of questioning in the classroom interaction. As a result, the teachers' questioning is only a superficial form of classroom activity, lacking in the practical value. It can't really stimulate students' initiatives, nor can it develop their interactive competence.

\section{Skills of Questioning in English Classes}

The validity of questioning relies on the skills of questioning. Norton (1989) and other researchers proposed some skills according to their research, they are sequence of questions, directing, probing, increasing waiting-time, encouraging student questions and so on. The skills of questioning involved four stages of questioning, they are preparation, asking question, students organizing answer, teacher providing the feedback. So the skills of questioning can divided into four parts: skills of preparing, designing, controlling and evaluating for questioning in English classes.

\subsection{Skills of Preparing for Questioning}

Effective questions request teachers make preparation before class. Even if some teachers can ask questions extemporaneously, sometimes the arrangement of questioning lack logic in many situations, or there are problems in language organization and the questions cannot make students use the knowledge or skills to answer as expected. So before asking questions in class, the preparation is required as follows:

\subsubsection{Deciding on the Purpose for Questioning}

Teachers ask questions with several goals and aims (Note 11): Different styles of lessons, teaching goals have corresponding questioning strategies. Teacher should take different skills and methods of questioning.

To lead learners in to the topic. (Note 12) The teacher should ask the students some preview questions to introduce the topic before the actual start of the classroom interaction. The purposes of doing so lie in two aspects: one is to arouse the learning interest and curiosity of the students for them to participate in the classroom activities promptly; the other is to direct the students to the actual process of the class interactions without having students feel bored and discouraged. And the students will automatically respond to the teacher with enthusiasm. Thus creating the satisfactory atmosphere in the classroom interaction is very important.

To check or test the learners' ability of understanding, or practical skills of language. (Note 13) In any classroom interaction, the teachers should know beforehand the basic abilities of the learners or the students to make their teaching more effective. The questions should be the basic facts of the reading materials or the general development of the stories. By these questions, the teacher will know how much and how well the students have grasped the reading materials and how well they can do in the classroom interaction. And this also gives an idea to the students how they should do in the classroom interaction.

In all, with the goals in mind, teachers can predetermine the types of questions they are going to ask. And the goals of teachers' questioning will affect some other aspects of questioning skills, including question designing, question controlling and handling students' responses. 


\subsubsection{Selecting Content for Questioning}

Teacher's questions give guidance to emphasis of students' study. It is very important for teachers to choose key contents to design questions. On the contrary, the questioning based on non-key contents will confuse students.

In classroom language teaching, students' learning is mainly based on teachers questioning, so the content teachers choose to question is quite important. This practice will lead the students to see the content that teachers view as important. If teachers have difficulties in building questions about all lessons, they should formulate questions prior to class, anticipating the range of students' possible responses. Ask focused, clearly worded questions that give students a clear indication of expectations for responses. (Note 14) Teachers should be sure that the content of the questions requires responses, corresponding with the purpose of the question. Do not ask students to name an example when what the teacher really wants is an explanation of an example. It may be a problem that the teacher is unsatisfied with students' responses. Analyze the questions and determine the kinds and levels of your questions. Ask questions which conform to the students' development level. If students are not knowledgeable in the content, teachers ask concrete level questions rather than abstract level questions.

\subsubsection{Phrasing the Questions}

The answer to questions should be more than just Yes/No. Questions should be clear and the students should easily be able to see what you want for a response. Do not confuse the students. Ask questions with understandable vocabulary. If students are unfamiliar with the terms that you use, it is unlikely that they will give you back what you are looking for. Use familiar terminology when phrasing questions. Be sure the questions you ask are clear in your own mind, and think through what you want from the students before you ask the questions. The questions teachers ask should be those that solicit student responses and provide instructional cues that convey the content to be learned or provide directions toward the content to be learned in a classroom setting. Questions are also used to help students know what they are to do and how they are to do it. Questioning should be challenging and interesting. It can stimulate the pursuit of knowledge and encourage passive students to get involved in. Answering questions should be brief, and try to avoid answering yes or no. Good question can stimulate students to discuss and think. Do not raise general questions, such as:

What about foreign affairs?

What did we say about chemical bending?

\subsubsection{Anticipating Problems}

The teacher can know the learners' inherent knowledge by asking them two kinds of questions: the one-word answer question and multi-answer question. (Note 12)The first question will show whether the students have grasped the knowledge. And the second question will show how well the learners can make use of the knowledge that they have grasped, and to what degree the learners can demonstrate their ability in communicating with others. By comparison, the second question appears more conducive to classroom interaction than in the first one. Therefore, when the teacher aims at eliciting information from students, they had better ask the second kind of questions. Teachers should predict the students' possible answers, and prepare to give some guidance to the questions. And the teacher should prepare for the situation where students cannot give the answer and students refuse to answer questions and so on.

\subsection{Skills of Designing for Questioning}

Compared with question planning, question designing is more closely connected with questioning skills and techniques. It refers to choosing the proper ways of asking questions and selecting the types of questions. Questioning designing strategy refers to methods and skills teachers choose to raise appropriate questions. In this part, the methods and skills include simplifying, moderating, asking thought-provoking questions, asking challenging questions, asking follow-up questions, asking questions relevant to students, and asking divergent questions.

\subsubsection{Increasing the Number of Referential Questions}

Referential questions are those questions for which the answer is not already known by the teacher. Such questions may require interpretations and judgments on the part of the "answerer". Display questions refer to those questions for which the questioner knows the answer beforehand; such questions are usually asked for comprehension checks, confirmation check, or clarification requests. It was further observed that referential questions produced more classroom interaction. Swain argues that output may be an important factor in successful second language acquisition. She suggests that output creates the necessity for the learner to perform a syntactic analysis of the language. She further notes that comprehending the input or getting the message is possible without such an analysis. Producing one's own messages, on the other hand, it may force the learner to pay attention to the means of expression to successfully convey his/her intended meaning. If it is true that such questions increase the amount of learner output, and if output leads to better learning, then questions can be an important tool in the language classroom, especially in those EFL contexts where the classroom provides the only opportunity to produce the target language. It was inferred from the obtained data that display questions require short answers containing small pieces of information, such as part of speech, word stress, 
intonation, antonyms and synonyms, word pronunciation and meaning, comprehension checks, etc. Brock and Long and Sato have reported that classroom interaction was characterized by the use of display questions. (Note 15) However, it seems that the use of display questions can encourage language learners, especially beginners, to get interested. It may also help teachers provide comprehensible input for learners. Referential questions, typical of content classrooms and high proficiency language classrooms, and usually requiring long and syntactically complex answers contain, in fact, important points, e.g. interpretation, elaboration, giving opinions, etc.

So, it would be dangerous to generalize that referential questions are more useful for language teaming or display ones are useless. Each context requires an appropriate strategy for itself. It is important for teachers to adjust their teaching style to learners' strategies.

\subsubsection{Asking Questions Related to Students}

There are always silent students in the class, and the silent students will always be there in the class. They should be encouraged to participate in the classroom activities or the classroom interactions. In order to get the silent students to be active in the class interactions, the teachers should develop some methods to arouse the learning interest of the silent students. The teacher should begin by asking some tentative questions to arouse the silent students instead of asking them what their opinions can be about the reading materials or their personal ideas about the phenomenon in the world of practice. And the students can participate in the interactions actively accordingly. And the question must related to students or the information known by students, if not, they will not interested in it or participate in it.

\subsection{Skills of Controlling for Questioning}

Since the focus of interactive teaching is interaction between teachers and students, in the course of teachers' questioning and students' answering, more efforts should be made on the controlling practice to enhance the interactive effect in language teaching. Some strategies employed by teachers are like these: sequencing, that is, arrange the questions from easy ones to more difficult; nominating after the question; nominating non-volunteers; question redirecting and probing; increasing wait-time and directing attention to all and so on. In this paper a few aspects are emphasized as follows:

\subsubsection{Nominating after the Question}

The way of questioning is asking questions first, giving students time to think and then ask nominating student to answer. If you nominate students before you asking question, there will be just the nominated student thinking this question, while the other students considered not involved.

\subsubsection{Nominating Non-volunteers}

Students become distracted easily or do something by their own. When teachers ask questions, they can ask silent students deliberately, it can let students pay attention to your class. Non- volunteers will think they are taken seriously when teachers ask a question to them. And they will feel very well and they will participate in classroom instructions after that, and they will feel spunky.

\subsubsection{Probing}

Probing is another important questioning skill. (Note 16) Probes are based on student responses. The initial response of students may be superficial. The instructor needs to use a questioning strategy called probing to make students explore initial comments. Probes are useful in getting students more involved in critical analysis of their own and other students' ideas. If the student does not provide a complete answer, he or she may know a partial answer. In some cases, even though the question is perfectly clear to the teacher; it might need to be restated or broken down into smaller pieces. The teacher should not accept "I don't know" as the final response.

Probing is the use of further questions to force the student to put together his or her partial knowledge into a more complete answer. Probing often involves the use of follow-on or leading questions to help the students answer the initial question or to provide a more complete answer. Probes can be used in different ways. Probes can be used to:

-Analyze a student's statement, make a student aware of underlying assumptions, or justify or evaluate a statement.

-Help students deduce relationships. Instructors may ask student to judge the implications of their statements or to compare and contrast concepts.

\subsubsection{Increasing Wait-time}

An important dimension of teacher's questioning skills is halting time, or wait time, that is, the length of time the teacher waits after asking the question before calling on a student to answer it, rephrasing the question., directing the question to another student, or giving the answer. (Note 17) That is called wait time, and it is amazing how few teachers use this important questioning skill. In fact, when we consider the steps that are involved for a second language speaker in answering a question, an argument can be made that he needs an even longer wait time than a native speaker. In fact, it seems clear that if teachers asked questions, which they did not already know the answers, they would find it natural 
to wait for responses, and they would need time to think about the responses before reacting to them.

It takes time to answer questions, a lot of studies shown in their investigations that students were rarely given sufficient time to formulate their answers before the teacher repeated, rephrased, or went on to ask another student the question. Rowe found that teachers, on average, waited less than a second before calling a student to respond, and that only a further second was then allowed for the student to answer before the teacher intervened, either supplying the required response themselves, rephrasing the question, or calling on some other student to respond. (Note 18) In short, few teachers give their students enough wait-time to think about the questions or to form meaningful answers. The average wait time, when the teacher waits at all after a question, is less than a second. There should be at least 2 to 4 seconds after any question before any student is called on to answer it. Wait time allows the reflective student a chance to respond and well as the impulsive student or one who instantly knew the answer. If no one wants to tackle the question after 15 seconds, leave it unanswered. Tell the students to think about the answer and you will raise the question again at the beginning of the next class period.

\subsubsection{Directing Attention to All}

In actual classroom interaction, the teacher will automatically cover high achievers, focus on the students in the first few rows and choose the selected few students to answer questions. And the teacher may not sometimes realize this when asking students questions. All these will result in the improper distribution of the questions to the students.

The solution to the imbalanced distribution of the students is to keep the teacher aware of the whole class in teaching activities, and the teacher should cover all the students in the classroom while focusing on high-achievers and low-achievers at the same time, thus arousing the leaning interest of all the students. And the teacher will pay attention to the whole class when asking the whole class the questions, not only high-achievers and low-achievers but also students of middle levels in the class. On the other hand, the teacher will generally ask the students in the first rows and the selected few students questions in the class. Distributing questions in this way also results in negative effects on students in that some students feel that they are neglected, thus decreases their learning interest in classroom activities.

There are generally two approaches to these problems in class activities. One is that the teacher should pay attention to the whole class when asking students questions. The other is that the teacher should ask questions to the whole class from simple to complicated degrees instead of focusing on the few students with difficult questions. That is, the teacher should get to know well about the personalities and individual needs of their students so that they can treat them respectively.

Distribute questions among students so that all have a chance to respond. Call on non-volunteers; students may have become dependent upon you to provide answers. Avoid depending upon the same few students to answer questions all the time. Their responses may not necessarily be representative of the larger group. Tactfully thank them for their continuous contributions, and ask for other volunteers. Call upon non-volunteers in a friendly non-threatening manner. Develop a questioning strategy: if you ask questions, do not allow only a few students to monopolize the responding. Opportunity to respond should be available to all. Note that teachers are likely to call on the same students, those who have the right answers to get the reinforcement of a correct answer. Engage many students; does not allow a minority of more confident or impulsive students to dominate the class. Present challenging and stimulating questions to all students, not just those perceived as having higher ability or knowledge. You may need to develop a plan if you want all students to participate.

\subsection{Skills of Evaluating for Questioning}

An important aspect of classroom interaction is the manner in which the instructor handles student responses. When an instructor asks a question, student can either respond, or give no response. The ways instructors handle students' responses are closely connected with the effect of the interaction. Teachers' feedback is very important. The feedback consists of positive feedback and negative feedback. Positive feedback is more helpful than negative feedback to improve the students' behavior and study motivation. Moreover, students are involved in the positive feedback of questions actively.

\subsubsection{Praising}

Affective Cognitive feedback gives students information about the questions they use, while affective feedback serves as emotional support which facilitates communication to continue. It is beneficial to learners' language development. Accompanied by positive affective feedback that is neither too discouraging to proceed nor so encouraging that learners see no need to change their output. To be exact, with the optimal affective feedback, positive feedback in the cognitive domain will serve as reinforcement of the forms used and neutral or negative feedback in the cognitive domain will encourage students to try again. Therefore, teachers must provide learners with cognitive feedback as well as affective support. 


\subsubsection{Encouraging}

In language classrooms, feedback is often directed towards the accuracy of what a student says. A number of issues are involved in error feedback. These include decisions about (1) whether learner errors should be corrected, (2) which kinds of learner errors should be corrected, and (3) how learner errors should be corrected. Even than students give a complete wrong answer, teacher still should give them enough encouragement.

For instance:

-Could you please make a further explanation?

-How do you support your ideas?

-Whether your answer is right or wrong, it doesn't matter. Please grasp the opportunity to practice your oral English.

-You've made great progress in pronunciation.

When students cannot give the correct answer to the question, teacher can ask another easier question as a cue to help students to obtain the correct answer. It can encourage them to answer questions.

\subsubsection{Quoting}

Quoting is one kind of indirect praises. Corrective feedback is a term that is often used indiscriminately with feedback in literature; there are nevertheless shades of meaning between two terminologies. Precisely speaking, corrective feedback is an extended form of feedback encompassing feedback and additional demonstrations or explanations intended to remedy particular problems in student learning. Sometimes it is also known as error correction from the perspective of Error Analysis. Teacher can quote students' correct answer when he gives students the standard answer. It can encourage more than praised or encouraged words.

\section{Conclusion}

English teaching is a process that the teacher interacts with students. Asking and answering are the primary ways to communicate with each other, so questioning plays a central role in English class. It urges students to think actively and develops their creative thinking. Of course, there is not a rigid method of questioning. In this paper the author discussed the skills of questioning and the benefit of skills of questioning in English class with some examples on the base of analyzing some basic knowledge of questions. It will contribute to the English teachers. However, putting the skill into practice should not be the final aim of the English teacher. They should devise questions carefully, considering the specific situations and using them correctly in class. Finally, developing feasible and rational questioning skills and teaching skills can meet the need of the country. As long as they do like that, our society will develop rapidly and education will become more and more advanced.

\section{References}

Brown, H. D. (1994). Principles of Language Learning and Teaching. New Jersey: Prentice Hall Regents Prentice Hall, Inc. pp.23-64.

Brock, C. A. (1986). The Effects of Referential Questions on ESL Classroom Discourse. Quarterly. 20: 47-59.

Chaudron, C. (1988). Second Language Classrooms: Research on Teaching and Learning. Cambridge: Cambridge University Press. pp.62.

Holland, R. \& T. Shortall. (1998). Classroom Research and Research Methods. Center for English Language Studies, Birmingham: Birmingham University Press. pp. 31-4.8

http://www.ou.edu/cos/english/comp/ASKINGQUESTIONS.htm.

Kanchak, D. \& P. D. Eggen. (1989). Learning and Teaching. Mass: Allyn and Bacon. pp. 24-56.

Kindsvatter, R. W. Willen. \& M. Ishler. (1988). Dynamics of Effective Teaching. New York: Longman. pp. 20-34.

Lier, LX. (1984). Analyzing Interaction in Second Language Classrooms. ELT Journal, Vol. 38, No. 3,160-167.

McDonough, J. \& C. Shaw. (1993). Materials and Methods in ELT. Oxford: Blackwell. pp. 41-70.

Morgan, N. \& Saxton, J. (1991). Teaching, Questioning, and Learning. New York: Routledge. pp. 43-79.

\section{Notes}

Note 1. Yao Hong-xi, Lessons Depend on Questioning-Questioning Skills of Junior English Class. English Teaching and Research of Midle School and Primary School. 2007(2),6.

Note 2. http://www.ou.edu/cas/english/comp/ASKINGQUESTIONS.htm.

Note 3. Ibid . 
Note 4. Holland, R. and T. Shortall . Classroom Research and Research Methods. (Center for English Language Studies, Birmingham: Birmingham University, 1998).

Note 5. Mc Donough, J. and C. Shaw. Materials and Methods in ELT. (Oxford: Blackwell,1993).

Note 6. Chaudron, C. .Second Language Classrooms: Research on Teaching and Learning. (Cambridge: Cambridge University Press, 1988).

Note 7. Nunan, D. Understanding Language Classrooms. (Hemel Hempstead, Herts: Prentice Hall, 1989).

Note 8. Kanchak, D. and P. D. Eggen. Learning and Teaching.( Mass: Allyn and Bacon, 1989).

Note 9. Richards, J. C. and C. Lockhart. Reflective Teaching in Second Language Classrooms. (Cambridge: Cambridge University Press, 1994).

Note 10. Kindsvatter, R. W. Willen.\& M. Ishler. Dynamics of Effective Teaching. (New York: Longman, 1988).

Note 11. Morgan, N. and Saxton, J. Teaching, Questioning, and Learning. (New York: Routledge, 1991).

Note 12. Ibid.

Note 13. Ibid.

Note 14. Hu Chun-dong. English Teaching Methodlogy. (Beijing: Higher Education Press,1990),226.

Note 15. Brock, C. A. The Effects of Referential Questions on ESL Classroom Discourse. (Quarterly 20: 1986.) 47-59.

Note 16. Ibid.,60-62.

Note 17. http://www.ou.edu/cas/english/comp/ASKINGQUESTIONS.htm.

Note 18. Ibid. 
Table 1. A Taxonomy of Question Types

\begin{tabular}{|c|c|c|}
\hline Question types & Explanation & Noted by \\
\hline Closed & Have a short, fixed answer, for example "What day is it today?" & Barnes \\
\hline Open & $\begin{array}{l}\text { Typically require a longer, less limited response, for example "What did you do } \\
\text { yesterday?" }\end{array}$ & \\
\hline Display & $\begin{array}{l}\text { Those to which the questioner already knows the answer and is merely testing } \\
\text { the respondent's knowledge or understanding. }\end{array}$ & Brown \\
\hline Referential & $\begin{array}{l}\text { Those to which the questioner does not know the answer and is genuinely } \\
\text { seeking information. }\end{array}$ & \\
\hline Procedural & $\begin{array}{l}\text { Relate to classroom, lesson and student control processes such as "Who is } \\
\text { absent today?" }\end{array}$ & $\begin{array}{l}\text { Richards } \\
\text { and } \\
\text { Lockhart }\end{array}$ \\
\hline Convergent & $\begin{array}{l}\text { Often have short answers which "encourage similar student responses" and } \\
\text { require low level thought processing, for example "Can you ski?" "Yes, I can." } \\
\text { "No, I can't." }\end{array}$ & \\
\hline Divergent & $\begin{array}{l}\text { Necessitate more wide-ranging, long responses with higher level thought } \\
\text { processing, for example "Why is the Beatle music so popular in Japan?" }\end{array}$ & \\
\hline Rhetorical & Those which the questioner answers him/herself. & \\
\hline \multirow[t]{3}{*}{ Interaction } & $\begin{array}{l}\text { Comprehension checks: "elicits assurance from the listener that a message has } \\
\text { been received correctly." }\end{array}$ & Chaudr \\
\hline & $\begin{array}{l}\text { Confirmation checks: assume a positive response and "allow the speaker to } \\
\text { correctly interpret reactions by the listener." }\end{array}$ & \\
\hline & $\begin{array}{l}\text { Clarification requests: similar to confirmation requests but with a more open } \\
\text { answer. }\end{array}$ & \\
\hline Instructional & $\begin{array}{l}\text { Any question presented in the classroom presupposes that the question is } \\
\text { intended to solicit learner production. }\end{array}$ & Van Lie \\
\hline Conversational & Any question asked outside the classroom & \\
\hline
\end{tabular}

Cited by Chaudron; (Note 6) Cited by Nunan (Note 7) 